\title{
UNIVERSITY-INDUSTRY COLLABORATION AS A DRIVE FOR INNOVATION IN EUROPE - A LITERATURE REVIEW WITH A SYSTEMATIC APPROACH
}

\section{${ }^{a}$ CSILLA PESTI, ${ }^{b}$ VIOLA TAMÁŠOVÁ, 'DANIEL LAJČIN, ${ }^{\mathrm{d}}$ EDIT BODONYI}

${ }^{a, d}$ Teacher Training Centre, Károli Gáspár University of the Reformed Church in Hungary, Dózsa György str. 25-27, 1146 Budapest, Hungary

b,c DTI University, Sládkovičova 533/20, 01841 Dubnica nad Váhom, Slovakia

email: ${ }^{a}$ pesti.csilla@kre.hu, 'bamasova@dti.sk, 'lajcin@dti.sk, dbodonyi.edit@kre.hu

This paper was prepared within the framework of the project titled Managerial competences and innovations in current educational practices (project ID: IGA 007VŠDTI/2020).

Abstract: The aim of our study is to systematically review existing literature from the Abstract. The aim of our study is to systematically review existing literature from the past five years on university-industry collaboration, with a special emphasis on their relation to innovation. We conducted a literature review with a systematic approach with the involvement of 29 studies from European countries, published between 2016 and 2020. Our results have revealed a rather homogeneous pattern of research studies focusing on university-industry collaboration in European countries.

Keywords: university-industry collaboration, innovation, literature review, Europe

\section{Introduction}

As the role of higher education is in a constant interplay with the contextual change processes, the universities are expected not only to reflect on societal and economic challenges, but to be active agents in tackling the emerging issues by co-creating knowledge with relevant stakeholders (Perkmann et al., 2013). This notion has strengthened the importance of partnerships between higher education institutions (HEIs) and external (nonand for-profit) organizations. A plethora of studies interpret universities' collaboration endeavours as a driving factor for innovation (Ankrah \& AL-Tabbaa, 2015), and although there is a growing body of valuable research contribution to the topic, mostly collaboration between universities and industry stakeholders (UIC) stands in the focus of scientific attention; therefore, there is a knowledge gap regarding HEIs' partnerships with other, non-profit-oriented bodies.

Reinforcing the attention on university-industry collaboration, systematic literature reviews from recent years provide valuable, comprehensive overview of the previously scattered knowledge (e.g. Ankrah \& AL-Tabbaa, 2015; Rybnicek \& Königsgruber, 2018; European Commission, 2018). Although there are few publications focusing on other, non-industry-university-oriented collaborations (e.g. Halász, 2016; Pesti et al., 2020), these contributions are either too discipline-specific or mostly of a case study nature, thus their generalizability is possible only in a narrower context.

Based on these cornerstones, the aim of our study is to systematically review existing literature from the past five years on university-industry collaboration, with a special emphasis on their relation to innovation. We conducted the literature review with a systematic approach along an overarching question: What are the most recent developments concerning partnerships in higher education? To grasp the essence of the reviewed literature, three research questions were formulated:

1. What patterns emerge from existing literature on universityindustry collaboration?

2. How can the innovative aspects of university-industry collaboration be characterized?

3. How do research papers from the past five years contribute to the knowledge on university-industry collaboration?

This paper first discusses partnerships in higher education, then, we introduce the methodology for our literature review with a systematic approach. The next chapter presents the results where we used the modules of the coding table as an organizing principle. Following this, we answer the research questions in the Analysis and discussion chapter. Finally, the paper is summarized in the last chapter that incorporates the conclusions.

\section{Materials and methods}

\subsection{Research design}

The aim of our study is to systematically review existing literature from the past five years (from 2016 to 2020) on university-industry collaboration, with a special emphasis on their relation to innovation. The study is guided by an overarching question of what the most recent developments concerning partnerships in higher education could be identified in literature.

In the literature review we adhered to a rigorous systematic approach along the PRISMA guidelines (Preferred Reporting Items for Systematic Reviews) (Moher et al., 2015) to ensure the transparency and replicability of the review process. Based on preliminary screening of literature, a review protocol was developed, which detailed various aspects of literature identification (such as eligibility criteria, information sources, search strategies), as well as considerations for recording literature (data management, selection process, data collection process) (a brief summary of the review protocol is presented in Appendix 1).

We sought peer-reviewed research papers on English language that were published between 2016 and 2020 and that were available through ProQuest database. Other eligibility criteria included some aspects of the population (publications must involve university/university staff OR higher education/higher education institution staff), and geographical considerations (we narrowed our review to literature focusing on European countries). Studies that were identified during the database search but were of a literature review type or non-empirical publications were recorded but excluded from further analysis. A set of key descriptors were used during database search, including synonyms for the higher education pillar (such as university, higher education, higher education institution, college), for the collaboration pillar (such as partnership, collaboration, cooperation, network). In order to ensure that studies focusing on the innovative aspect of the partnership were identified, the search string was amended with the innov* term.

\subsection{The process of identifying the studies}

Having the review protocol developed and accepted, the next step was to identify studies through database search, which happened in four phases (Figure 1):

1. The search string described above returned 10,281 records, from which 10,033 were eliminated before screening by the use of various automation tools (especially checking eligibility for peer-reviewed studies, language, and geographical scope).

2. 248 studies were selected for screening, which included the reading of the title and the abstracts by one researcher. As a result, 66 records were excluded from further reviewing due to either being a review, not relying on empirical data, not focusing on partnerships in higher education or not being accessible.

3. 182 reports were assessed for eligibility. Firstly, a set of 40 studies (approximately $22 \%$ of all the selected studies) were assessed independently by two researchers, and in case of discrepancies in their assessment (this occurred in case of two studies), they discussed the reasons, came to a joint conclusion, and clarified the review protocol for further assessment with the aim to ensure consistency. Following this, the remaining studies were assessed by one researcher. 
We used a reference management system (Mendeley) throughout the identification, screening, and inclusion phases. Studies included in the review are listed in Appendix 2.

Figure 1: PRISMA flow diagram for systematic reviews (adapted from Page et al. (2020))

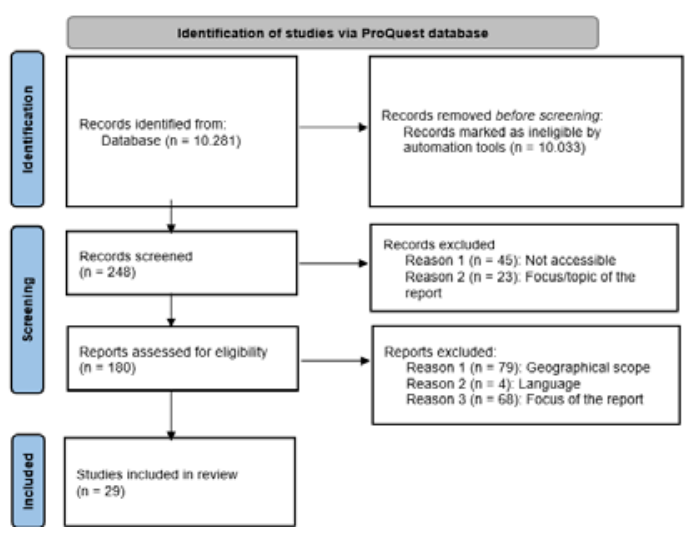

\subsection{Data collection and analysis}

Parallel with the screening process, we developed a code system for extracting data from the included studies $(n=29)$ for further analysis. The code system included seven modules with several categories:

1. General information (descriptive data): authors, year, title, relevant discipline, geographical scope;

2. Keywords defined by the authors of the studies;

3. Methodology: research design, aims

4. Characteristics of the collaboration: participators, level of formality, leader of the collaboration, special focus, activities;

5. Innovative aspects: linkage to innovation;

6. Main findings;

7. Coder's description and impressions.

After the code system development, we conducted double coding with five studies (two researchers coded the same five studies individually). The level of consistency of the double coding was high, therefore the remaining studies were coded by one researcher.

The coded data was suitable for further, quantitative, and qualitative analysis. Concerning some categories (e.g. keywords), we quantified the data, and used IBM SPSS ${ }^{\circledR}$ Statistics 25 for quantitative analysis; while in the case of some other categories, a thematic analysis proved to be a suitable step forward in order to identify common themes in data (e.g. aims, main findings) - MAXQDA, a software aiding qualitative analysis was used. Appendix 3 illustrates a more specific summary of the code system, data analysis and their relation to research questions.

\section{Results}

\subsection{General information (descriptive data)}

In our literature review we included studies presenting empirical research from a European country, published between 20162020: there are two studies from 2016, six studies from 2017, nine studies from 2018, five studies from 2019, and seven studies from 2020. Regarding the geographical distribution of selected studies, only Italy stands out with six publications, while the other countries are represented in our sample with one, two or three studies (Figure 2 summarizes the descriptive frequencies of country-related data).
Concerning the geographical scope that the studies cover, we coded for four categories (international, national, regional, institutional). Dominantly, the two extreme categories (international as the widest scope (34.5\%) and institutional (31.0\%) as the narrowest scope) are represented in the selected studies.

Figure 2: Frequencies of selected studies per country, count $(\mathrm{n}=29)$

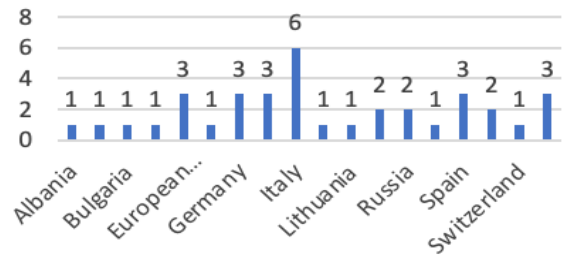

\subsection{Keywords identified in the selected studies}

Throughout the 29 selected studies, we recorded 152 keywords defined by the authors, and after carefully reviewing them, 4 main themes, and 13 sub-thematic groups emerged (Figure 3 ).

Figure 3: Occurrence of keywords associated with the selected studies by their authors along the identified themes and subthematic groups, count $(n=152)$

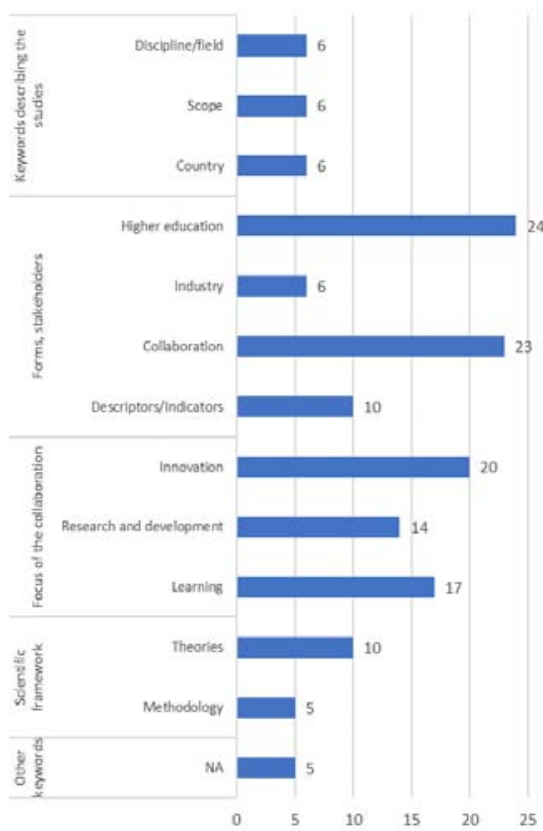

The first theme consists of groups of descriptive keywords. Only a small number of studies used specific keywords for indicating the discipline (e.g. industrial biotechnology, digital technologies), and although UIC is a context-specific endeavour, just 6 studies indicated the country of origin clearly with the keywords.

The second theme includes groups of keywords concerning the form of collaboration and its stakeholders. Although the data is not representative, it must be emphasised, that keywords related to the university (or to its associates, students, etc.) as a participant in the collaboration occur 4 times more often, than keywords related to the industry. Keywords referring to the form of collaboration are rather homogeneous (e.g. university-industry collaboration, cooperation, relationship, network, etc.), merely a few studies indicate differing terms, such as clusters $(n=2)$, intermediation $(n=1)$, or joint experience $(n=1)$.

The third theme consists of keyword-groups that relate to the focus of the collaboration. Keywords in the innovation group are rather diversified and specific (e.g. user innovation, social 
innovation, innovation competences, etc.); the only keywords that appear in more studies are innovation performance $(n=2)$, and open innovation $(n=3)$. Similarly to the previous one, the group of research and development $(\mathrm{R} \& D)$ is rich in various keywords, however, sustainability emerges to be a major focus of research papers ( 6 research papers indicated this focus in their list of keywords). At last, but not least, in the group of learningrelated keywords one might find terms concerning knowledge (e.g. knowledge transfer), IT (e.g. gamification, serious video games), and competence development (e.g. skills training).

The fourth theme includes two sub-groups, referring to the theoretical and methodological framework of the studies. Regarding the theories that the selected studies rely on, the triple helix model of innovation occurs as a keyword in the case of 5 studies.

\subsection{Methodology of the selected studies}

During the coding, methodological data was also extracted from the selected studies (Figure 4). This has revealed that most of the studies are of a quantitative design (34.5\%). We found it important to highlight the high occurrence of case studies as well $(27.6 \%)$ - in these studies the authors have not defined explicitly whether they relied on a quantitative, qualitative, or mixed design. With 13.8 , purely qualitative research is the least applied one.

Figure 4: Distribution of types of research in the selected studies, $\%(n=29)$

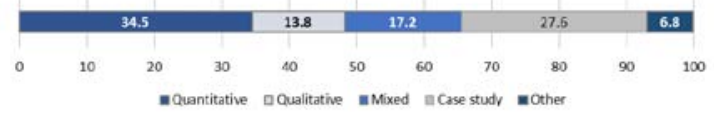

3.4 Characteristics of the collaboration described in the selected studies

First, we observed who are the participants of the collaboration in the selected studies, and besides higher education (it appeared as a participant in every study) we identified four main categories:

1. industry ( $\mathrm{n}=25$, e.g. from small and medium size firms to big corporate organizations),

2. society ( $n=6$, e.g. civil organizations),

3. research and innovation $(n=4$, e.g. research institutions, innovation clusters),

4. authorities ( $\mathrm{n}=3$, e.g. city council, national authorities).

Almost $40 \%$ of the studies $(n=11)$ explicitly indicated that the collaboration they dealt with was of a formal nature (e.g. established partnership contracts), but in most of the studies this characteristic was not that straightforward. This uncertainty remained with the next coded category, concerning the leader of the collaboration: none of the selected studies indicated explicitly whether the university or other participants are the leaders of the collaboration.

Figure 5: Results of the thematic analysis regarding the focus of collaboration, count $(n=29)$

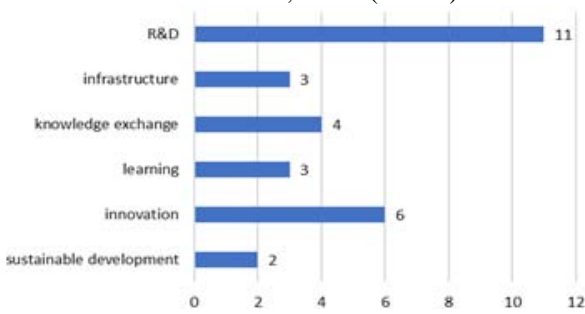

We conducted a thematic analysis on the extracted textual data describing the focus of the collaboration (Figure 5), which has revealed that $R \& D$ is the most common aim for and of collaboration, followed by innovation, and knowledge exchange.

\subsection{Innovative aspects of the collaboration described in the selected studies}

Without any exception, the selected studies were explicitly linked to innovation by their authors. The thematic analysis of the extracted data from the studies revealed 8 thematic focuses concerning the innovative aspects of the collaboration between HEIs and other participants (Figure 6):

- Social innovation appeared in five studies, and was commonly linked to the universities' third mission, focusing on the social development of their narrower region (Aleffi et al., 2020; Birkner et al., 2017; Farré-Perdiguer et al., 2016; Meyer et al., 2018; Mititelu et al., 2017).

- Four studies explicitly mentioned some innovative forms of collaboration, such as partnerships between innovation clusters and HEIs, universities acting as business incubators, or the presence of intermediary organisations between universities and other participants (Edmunds et al., 2019; Blix Germundsson et al., 2020; Lysenko et al., 2020; Oplakanskaia et al., 2019).

- The theme of learning also appeared among the most frequent once, indicating that the collaborating participants interpret innovation in the context of learning that covers competence development, and professional development (Abelha et al., 2020; Adomavičiūtė, 2018; Rojo et al., 2019; Secundo et al., 2017).

- Two studies reported on the innovative aspects of collaboration through the joint establishment, development and/or use of infrastructure (such as commercial laboratories or scientific/technological/innovation parks) (Bergquist et al., 2019).

- Although less stressed, and with more tangible definitions, two-two studies connected the innovative aspects of collaboration to R\&D activities in general (Capaldo et al., 2016; Yordanova, 2018) and economic development (Abelha et al., 2020; Farré-Perdiguer et al., 2016).

- At last, but not least, one-one studies explicitly interpreted the innovative aspects of collaboration in the context of open innovation and environmental innovation (Lukac \& Chatzimichailidou, 2017).

Figure 6: Innovative aspects of collaboration in the selected studies, count $(\mathrm{n}=29)$

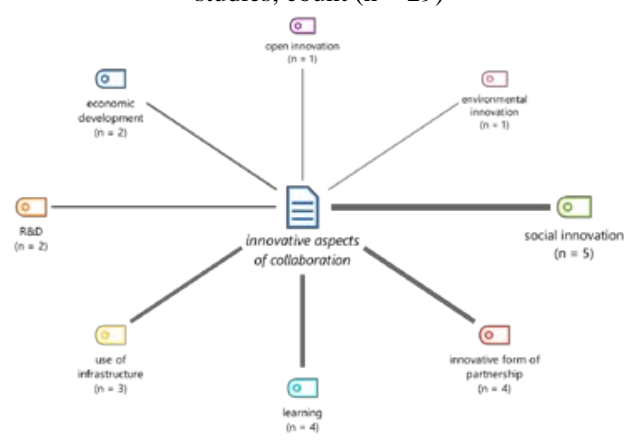

3.6 Main findings focusing on the impact of collaborations in the selected studies

The thematic analysis of the selected studies' main findings revealed a somewhat more nuanced pattern regarding their focus then the innovative aspects of collaboration presented in the previous chapter.

Hereby we present the various positive and negative impacts of collaborations $(n=18)$, since most of the studies referred to them in their findings:

- a positive impact on firms' performance in general and specifically on financial performance (Albats et al., 2018; Di Maria et al., 2019; Guzzini \& Iacobucci, 2017);

- a positive impact on the higher education system in general, including the enhancement of students' mobility and 
graduates' participation in the (global) labour market (Albats et al., 2018; Di Maria et al., 2019; Lysenko et al., 2020), but a negative impact on university-based professors' performance (Di Maria et al., 2019);

- a positive impact of universities as agents of intermediation on knowledge transfer (Farré-Perdiguer et al., 2016; Oplakanskaia et al., 2019);

- a positive impact on the development process regarding new production technologies, further co-patents, innovative infrastructure, education and training (Lysenko et al., 2020; Murgia, 2018), including attracting investments for further development (Lysenko et al., 2020).

\section{Discussion}

In this chapter we summarize our analysis and findings and present them along the three research questions.

RQ1: What patterns emerge from existing literature on university-industry collaboration?

Although our sample of 29 selected studies for the review is not representative, some patterns have emerged that can be valuable for developing further research directions. Based on our results, most studies are either of an international (e.g. Abelha et al., 2020; Prokop et al., 2018) or an institutional (e.g. Levrouw et al., 2020; Mititelu et al., 2017) geographical scope. Interestingly, although partnerships in higher education influence a wider scope (e.g. settlement, region, state), only a few studies focused on such collaboration on the regional level (e.g. Jahic \& PilavVelic, 2020; Aleffi et al., 2020). Moreover, since the policy environment is also an influential factor regarding the efficiency and impact of partnerships on economical and societal developments, it is important to highlight the low number of studies dealing with HEIs' partnerships on a national level (e.g. Secundo et al., 2017; Murgia, 2018).

Concerning the participants of partnerships, most studies focused on university-industry collaboration (and this resonates with the findings presented in RQ3). Civil organizations, research institutions or authorities appeared only in a small number of studies, and as a third party in university-industry collaboration (e.g. Birkner et al., Oplakanskaia et al., 2019). Therefore, although we kept our search strategy open for any kind of partnerships in higher education, in the selected database, for the selected time period, only such studies could be identified that had relation to the industry.

RQ2: How can the innovative aspects of university-industry collaboration be characterized?

All the selected studies $(n=29)$ are linked to innovation, and although in most cases the authors were very explicit about the innovative aspects of the partnership, some studies just established this connection on a superficial level (e.g. stating that collaboration affects innovation). Data has revealed that social innovation and learning are two among the most common themes concerning the innovative aspects of partnerships.

RQ3: How do research papers from the past five years contribute to the knowledge on university-industry collaboration?

Around third of the selected studies were of a quantitative nature (e.g. Edmunds et al., 2019; Farré-Perdiguer et al., 2016 ), and, not so surprisingly, the occurrence of case studies was also high (27,6\%, (e.g. Adomavičiūte, 2018; Albats et al., 2018)) - this resonates with the number of studies with an institutional scope (we presented this finding under RQ1). This finding - although only to an extent due to the limited number of reviewed studies draws the boundaries of the current research scenario of partnerships in higher education.

Data concerning the focus of collaboration in the selected studies revealed that most partnerships aim to foster joint research and development (e.g. Capaldo et al., 2016) or innovation (e.g. Edumnds et al., 2019). Although in fewer studies, but for future research might be interesting to draw out, that knowledge exchange (e.g. Di Maria et al., 2019) infrastructure development (e.g. Jahic \& Pilav-Velic, 2020), learning (e.g. Meyer et al., 2018) and sustainable development (e.g. Mititelu et al., 2017) also emerged as themes concerning the focus collaboration.

Results from the thematic analysis of the research findings reported in the selected studies has revealed a rich map of contributions. Impact of the collaboration and indicators of the collaboration proved to be dominant themes in the extracted research findings (18 studies reported on it). Further analysis of the impact of the collaboration showed, that most studies identified positive impacts of UICs (e.g. on firms' performance, on the higher education system, on knowledge transfer, on technology production, on education and training etc.).

\section{Conclusions}

The changing societal-economical expectations from higher education raises such new challenges that stand in urgent need for collaboration between relevant stakeholders. This collaboration is commonly interpreted as a driver for innovation at micro, macro, and meso levels, and although the widely applied triple helix model of innovation (Etzkowitz \& Leydesdorff, 2000) emphasises the interactions between academia, industry and government, literature suggest that university-industry collaboration is (and for years has been) in the centre of scientific attention. Based on these cornerstones, our study aims to systematically review scientific literature published between 2016 and 2020, focusing on universityindustry collaboration. We also devoted a special emphasis on how these studies relate to innovation.

In our literature review with a systematic approach, we adhered to the premises of the PRISMA guidelines for conducting systematic literature review; however, the study has some limitations that one must consider. These limitations include the chosen database (we identified studies in one online database), restrictions on the language (studies published in English were selected), or the short time period (our review covers 5 years). Despite these limitations, the results contribute to the evergrowing body of knowledge on partnerships in higher education through its attempt to reveal the characteristics of not only UIC, but partnerships of any kind, in general.

However, our results have revealed a rather homogeneous pattern of research focusing on partnerships in higher education, since most of the selected studies (1) are of an international or institutional scope, (2) dominantly have university-industry collaboration as a focus, and (3) are of a quantitative or case study design. This can be the starting point of future research aiming to elaborate on partnerships in higher education in more depth.

\section{Appendices}

\section{Appendix 1. Review protocol}

Review questions

1. What patterns emerge from existing literature on partnerships in higher education?

2. How can the innovative aspects of partnerships in higher education be characterized?

3. How do research papers from the past five years contribute to the knowledge on partnerships in higher education?

Key descriptors/key terms

- Synonyms for the higher education part: university, higher education, higher education institution, college

- Synonyms for the collaboration part: partnership, collaboration, cooperation, network

- Innovation

Population: The publication MUST involve:

- university/university staff OR higher education/higher education staff,

- AND other actor/staff from another institution.

Databases

- ProQuest

Time period 
- $2016-2020$

Language

- English

Type of publication

- peer-reviewed journals

Geographical focus

- Europe

- Special focus on the V4 countries

Criteria for exclusion at any point of the process

- population does not meet the criteria

- publication time does not meet the criteria

- language does not meet the criteria

- type of publication does not meet the criteria

- geographical focus does not meet the criteria

- reviews and non-empirical publications will be recorded, but excluded from further analysis

Search strings:

(ti(universit* OR "higher education" OR college) AND ab(partnership* OR collaborat* OR cooperat* OR network*) AND ab(innov*) AND stype.exact("Scholarly Journals") AND la.exact("English") AND at.exact("Article")) AND la.exact("ENG") AND PEER(yes))

\section{Appendix 2. Selected studies for the literature review}

\begin{tabular}{ccc} 
Year & $\begin{array}{c}\text { Number of } \\
\text { selected studies }\end{array}$ & Selected studies \\
\hline 2016 & 2 & Capaldo et al. (2016), Farré-Perdiguer et al. (2016) \\
\hline 2017 & 6 & $\begin{array}{c}\text { Birkner et al. (2017), Guzzini \& Iacobucci (2017), } \\
\text { Lukac \& Chatzimichailidou (2017), Mititelu et al. } \\
\text { (2017), Runiewicz-Wardyn (2017), Secundo et al. } \\
\text { (2017) }\end{array}$ \\
\hline \multirow{2}{*}{2018} & 9 & $\begin{array}{c}\text { Adomavičiùté (2018), Albats et al. (2018), } \\
\text { Kaklauskas et al. (2018), Kobarg et al. (2018), } \\
\text { Meyer et al. (2018), Murgia (2018), Pleśniarska } \\
\text { (2018), Prokop et al. (2018), Yordanova (2018) }\end{array}$ \\
\hline 2019 & 5 & $\begin{array}{c}\text { Bergquist et al. (2019), Di Maria et al. (2019), } \\
\text { Edmunds et al. (2019), Oplakanskaia et al. (2019), } \\
\text { Rojo et al. (2019) }\end{array}$ \\
\hline & & $\begin{array}{c}\text { Abelha et al. (2020), Aleffi et al. (2020), } \\
\text { Germundsson et al. (2020), Huggins et al. (2020), } \\
\text { Jahic \& Pilav-Velic (2020), Levrouw et al. (2020), } \\
\text { Lysenko et al. (2020) }\end{array}$
\end{tabular}

Appendix 3. Code system used for data collection, type of data and analysis in relation with the research questions

\begin{tabular}{|c|c|c|c|}
\hline & Category & Data & $\begin{array}{l}\text { Research } \\
\text { question }\end{array}$ \\
\hline \multirow{6}{*}{ 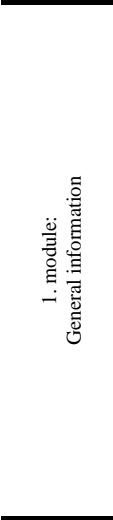 } & Author & $\begin{array}{l}\text { Extracted from the } \\
\text { database } \\
\text { ID data, not used in } \\
\text { analysis }\end{array}$ & NA \\
\hline & Title & $\begin{array}{l}\text { Extracted from the } \\
\text { database } \\
\text { ID data, not used in } \\
\text { analysis }\end{array}$ & NA \\
\hline & $\begin{array}{l}\text { Year of } \\
\text { publication }\end{array}$ & $\begin{array}{l}\text { Extracted from the } \\
\text { database } \\
\text { Descriptive statistics }\end{array}$ & NA \\
\hline & Discipline & $\begin{array}{l}\text { Coded data } \\
\text { Descriptive statistics } \\
\text { (quantified) }\end{array}$ & NA \\
\hline & Country & $\begin{array}{l}\text { Extracted from the } \\
\text { database } \\
\text { Descriptive statistics } \\
\text { (quantified) }\end{array}$ & NA \\
\hline & $\begin{array}{l}\text { Geographical } \\
\text { scope }\end{array}$ & $\begin{array}{l}\text { Coded data } \\
\text { Descriptive statistics } \\
\text { (quantified) }\end{array}$ & RQ1 \\
\hline 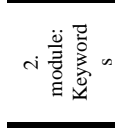 & Keywords & $\begin{array}{l}\text { Extracted from the } \\
\text { database } \\
\text { Thematic analysis, then } \\
\text { descriptive statistics } \\
\text { (quantified) }\end{array}$ & RQ3 \\
\hline \multirow{2}{*}{ 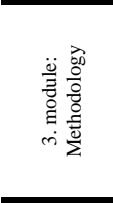 } & Research design & $\begin{array}{l}\text { Coded data } \\
\text { Descriptive statistics } \\
\text { (quantified) }\end{array}$ & RQ3 \\
\hline & Aims & $\begin{array}{l}\text { Quotation extracted from } \\
\text { the study } \\
\text { Thematic analysis, then } \\
\text { descriptive statistics } \\
\text { (quantified) }\end{array}$ & NA \\
\hline \multirow{2}{*}{ 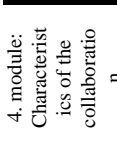 } & Participators & $\begin{array}{l}\text { Coded data } \\
\text { Descriptive statistics } \\
\text { (quantified) }\end{array}$ & RQ1 \\
\hline & $\begin{array}{l}\text { Level of } \\
\text { formality }\end{array}$ & $\begin{array}{l}\text { Coded data } \\
\text { Descriptive statistics } \\
\text { (quantified) }\end{array}$ & RQ1 \\
\hline
\end{tabular}

\begin{tabular}{|c|c|c|c|}
\hline & $\begin{array}{l}\text { Leader of the } \\
\text { collaboration }\end{array}$ & $\begin{array}{l}\text { Coded data } \\
\text { Descriptive statistics } \\
\text { (quantified) }\end{array}$ & RQ1 \\
\hline & $\begin{array}{l}\text { Focus of the } \\
\text { collaboration }\end{array}$ & $\begin{array}{l}\text { Quotation extracted from } \\
\text { the study } \\
\text { Thematic analysis, then } \\
\text { descriptive statistics } \\
\text { (quantified) }\end{array}$ & RQ4 \\
\hline \multirow{2}{*}{ 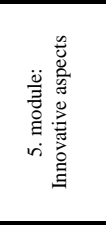 } & $\begin{array}{l}\text { Is the } \\
\text { collaboration } \\
\text { linked to } \\
\text { innovation? }\end{array}$ & $\begin{array}{l}\text { Coded data } \\
\text { Descriptive statistics } \\
\text { (quantified) }\end{array}$ & RQ2 \\
\hline & $\begin{array}{l}\text { What are the } \\
\text { innovative } \\
\text { aspects? }\end{array}$ & $\begin{array}{l}\text { Quotation extracted from } \\
\text { the study } \\
\text { Thematic analysis, then } \\
\text { descriptive statistics } \\
\text { (quantified) }\end{array}$ & RQ2 \\
\hline 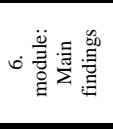 & $\begin{array}{l}\text { What are the } \\
\text { main findings of } \\
\text { the study? }\end{array}$ & $\begin{array}{l}\text { Quotation extracted from } \\
\text { the study } \\
\text { Thematic analysis, then } \\
\text { descriptive statistics } \\
\text { (quantified) }\end{array}$ & RQ3 \\
\hline 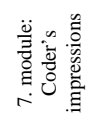 & $\begin{array}{l}\text { What are the } \\
\text { general } \\
\text { impressions after } \\
\text { reading the } \\
\text { study? }\end{array}$ & $\begin{array}{l}\text { Comments of the coder } \\
\text { Not used in analysis }\end{array}$ & NA \\
\hline
\end{tabular}

Literature:

1. Abelha, M., Fernandes, S., Mesquita, D., Seabra, F., \& Ferreira-Oliveira, A. T. (2020). Graduate employability and competence development in higher education - A systematic literature review using PRISMA. Sustainability, 12(15), 5900. doi: https://doi.org/http://dx.doi.org/10.3390/su12155900

2. Adomavičiūte, D. (2018). University's role and influence for professional development in public administration Area. Journal of the Knowledge Economy, 9(2), 703-719. doi: https://doi.org/http://dx.doi.org/10.1007/s13132-016-0360-1 3. Albats, E., Fiegenbaum, I., \& Cunningham, J. A. (2018). A micro level study of university industry collaborative lifecycle key performance indicators. Journal of Technology Transfer, 43(2), 389-431. doi: https://doi.org/http://dx.doi.org/10.100 7/s10961-017-9555-2

4. Aleffi, C., Tomasi, S., Ferrara, C., Santini, C., Paviotti, G., Baldoni, F., \& Cavicchi, A. (2020). Universities and wineries: Supporting sustainable development in disadvantaged rural areas. Agriculture, 10(9), 378. doi: https://doi.org/http://dx. doi.org/10.3390/agriculture10090378

5. Ankrah, S., \& AL-Tabbaa, O. (2015). University-industry collaboration: A systematic review. Scandinavian Journal of Management, 31, 387-408. doi: http://dx.doi.org/10.1016/j.sca man.2015.02.003

6. Bergquist, D., Hempel, C. A., \& Green, J. L. (2019). Bridging the gap between theory and design: A proposal for regenerative campus development at the Swedish university of agricultural sciences. International Journal of Sustainability in Higher Education, 20(3), 548-567. doi: https://doi.org/http:/ /dx.doi.org/10.1108/IJSHE-04-2019-0143

7. Birkner, Z., Máhr, T., \& Berkes, N. R. (2017). Changes in responsibilities and tasks of universities in regional innovation ecosystems. Nase Gospodarstyo NG, 63(2), 15 -21. doi: https://doi.org/http://dx.doi.org/10.1515/ngoe-2017-0008

8. Capaldo, G., Costantino, N., Pellegrino, R., \& Rippa, P. (2016). Factors affecting the diffusion and success of collaborative interactions between university and industry. Joumal of Science and Technology Policy Management, 7(3), 273-288. doi: https://doi.org/http://dx.doi.org/ 10.1108/JSTPM-12-2015-0038

9. Edmunds, L. D., Gluderer, S., Ovseiko, P. V, Kamerling, R., Ton, J., Vis, L., Jenni, M., Tutton, G., Lawton-Smith, H., Völgyiné Nadabán, M., Rab, M., Rees, J., Anson, J., Rushforth, A.D., Allen, M., Buchan, A.M., Vendrell, M., Casta, A., Mehes, G., ... Haassan, A.B (2019). New indicators and indexes for benchmarking university-industry-government innovation in medical and life science clusters: results from the European FP7 Regions of Knowledge HealthTIES project. Health Research Policy and Systems, 17 . doi: https://doi.org/http://dx. doi.org/10.1186/s12961-019-0414-5

10. Etzkowitz, H., \& Leydesdorff, L. (2000). The dynamics of innovation: from national systems and "Mode 2 " to a triple helix 
of university-industry-government relations. Res Policy, 29, 109-123. doi: https://doi.org/10.1016/s0048-7333(99)00055-4 11. European Commission (2018). The state of universitybusiness cooperation in Europe: Final report. Luxembourg: Publications Office of the European Union. https://www.ubcooperation.eu/pdf/final_report2017.pdf

12. Farré-Perdiguer, M., Sala-Rios, M., \& Torres-Solé, T. (2016). Network analysis for the study of technological collaboration in spaces for innovation. Science and technology parks and their relationship with the university: Revista de Universidad y Sociedad del Conocimiento. International Journal of Educational Technology in Higher Education, 13, 1-12. doi: https://doi.org/http://dx.doi.org/10.1186/s41239-016-0012-3

13. Germundsson, L. B., Augustinsson, S., \& Lidén, A. (2020). Collaboration in the making - Towards a practice-based approach to university innovation intermediary organisations. Sustainability, 12(12), 5142. doi: https://doi.org/http://dx.doi.or g/10.3390/su12125142

14. Guzzini, E., \& Iacobucci, D. (2017). Project failures and innovation performance in university-firm collaborations. Journal of Technology Transfer, 42(4), 865-883. doi: https://doi.org/http://dx.doi.org/10.1007/s10961-016-9554-8 15. Halász, G. (2016, May 13). Issues Paper. Seminar co-hosted by ELTE Doctoral School of Education and MiskolcHejőkeresztúr KIP Regional Methodological Centre, Budapest. http://halaszg.ofi.hu/download/May_13_Issues_paper.pdf

16. Huggins, R., Prokop, D., \& Thompson, P. (2020). Universities and open innovation: the determinants of network centrality. Journal of Technology Transfer, 45(3), 718-757. doi: https://doi.org/http://dx.doi.org/10.1007/s10961-019-09720-5 17. Jahic, H., \& Pilav-Velic, A. (2020). STEM on demand - Can current state of higher education infrastructure meet expectations? Nase Gospodarstvo NG, 66(3), 48 -55. doi: https://doi.org/http://dx.doi.org/10.2478/ngoe-2020-0017

18. Kaklauskas, A., Banaitis, A., Ferreira, F. A. F., Ferreira, J. J. M., Amaratunga, D., Lepkova, N., Ubarté, I., \& Banaitienė, N. (2018). An evaluation system for university-industry partnership sustainability: Enhancing Options for Entrepreneurial Universities. Sustainability, 10(1), 119. doi: https://doi.org/htt p://dx.doi.org/10.3390/su10010119

19. Kobarg, S., Stumpf-Wollersheim, J., \& Welpe, I. M. (2018). University-industry collaborations and product innovation performance: the moderating effects of absorptive capacity and innovation competencies. Journal of Technology Transfer, 43(6), 1696-1724. doi: https://doi.org/http://dx.doi.org/10.1007/s10 961-017-9583-y

20. Levrouw, L. M., van Lubek, Z., \& Smulders, F. (2020). Suspense as a driver for university-industry collaboration. Journal of Higher Education Theory and Practice, 20(13), 66-78. https://www.proquest.com/scholarly-journals/suspense-asdriver-university-industry/docview/2492325952/se2? accountid=30109

21. Lukac, D., \& Chatzimichailidou, M.M. (2017). Common sense approach as a basis for successful university-industry cooperation. Acta Technica Corviniensis - Bulletin of Engineering, 10(1), 91-96. https://www.proquest.com/scholarlyjournals/common-sense-approach-as-basis-

successful/docview/1869485890/se-2?accountid=30109

22. Lysenko, I., Stepenko, S., \& Dyvnych, H. (2020). Indicators of regional innovation clusters' effectiveness in the higher education system. Education Sciences, 10(9), 245. doi: https://doi.org/http://dx.doi.org/10.3390/educsci10090245

23. Maria, E. Di, De Marchi, V., \& Spraul, K. (2019). Who benefits from university-industry collaboration for environmental sustainability? International Journal of Sustainability in Higher Education, 20(6), 1022-1041. doi: https://doi.org/http://dx.doi.org/10.1108/IJSHE-10-2018-0172

24. Meyer, J., Pillei, M., Zimmermann, F., \& Stöglehner, G. (2018). Customized education as a framework for strengthening collaboration between higher education institutions and regional actors in sustainable development-Lessons from Albania and Kosovo. Sustainability, 10(11), 3941. doi: https://doi.org/http:// dx.doi.org/10.3390/su10113941

25. Mititelu, C., Fiorani, G., \& Litardi, I. (2017). Fostering sustainable development and entrepreneurship: The New Role of University. Management Dynamics in the Knowledge Economy,
5(3), 395-414. doi: https://doi.org/http://dx.doi.org/10.250 19/MDKE/5.3.05

26. Moher, D., Shamseer, L., Clarke, M. et al. (2015). Preferred reporting items for systematic review and meta-analysis protocols (PRISMA-P) 2015 statement. Systematic Reviews 4(1). doi: https://doi.org/10.1186/2046-4053-4-1

27. Murgia, G. (2018). The impact of collaboration diversity and joint experience on the reiteration of university co-patents. Journal of Technology Transfer, 1-36. doi: https://doi.org/h ttp://dx.doi.org/10.1007/s10961-018-9664-6

28. Oplakanskaia, R. V., Osmuk, L. A., Pogorelskaya, A., \& Pomorina, I. (2019). Post-industrial university towns and the triple helix concept: case studies of Bristol, Sheffield, Novosibirsk and Tomsk. Bulletin of Geography. SocioEconomic Series, 44(44), 39-46. doi: https://doi.org/ht tp://dx.doi.org/10.2478/bog-2019-0013

29. Page, M.J., McKenzie, J.E., Bossuyt, P.M., Boutron, I., Hoffmann, T.C., et al. (2020). The PRISMA 2020 statement: an updated guideline for reporting systematic reviews. BMJ 2021;372:n71. doi: https://doi.org/10.1136/bmj.n71

30. Perkmann, M., Tartari, V., Mckelvey, M., Autio, E., Broström, A., D'este, P., Fini, R., Geuna, A., Grimaldi, R., Hughes, A., Krabel, S., Kitson, M., Llerena, P., Lissoni, F., Salter, A., \& Sobreno, M. (2013). Academic engagement and commercialisation: A review of the literature on universityindustry relations. Research Policy, 42, 423-442. doi: https://doi.org/10.1016/j.respol.2012.09.007

31. Pesti, Cs. Kovacs, H., Saád, J., Thant Sin, K.K., \& Yunga, D. (2020). A literature review with a strong systematic aspect of school-university partnerships. In T. Baráth, L. Cervantes, G. Halász, H. Kovacs, D. Nurmukhanova, et al. (Eds.). Schooluniversity partnerships: Insights from an international doctorate program on teacher education (23-35). Budapest - Szeged: Eötvös Loránd University (ELTE) - University of Szeged, Hungarian-Netherlands School of Educational Management (SZTE, KÖVI). https://edit.elte.hu/xmlui/handle/10831/50583

32. Pleśniarska, A. (2018). The intensity of university-business collaboration in the EU. Acta Universitatis Lodziensis. Folia Oeconomica, (339), 147-160. doi: https://doi.org/http://dx. doi.org/10.18778/0208-6018.339.09

33. Prokop, V., Odei, S. A., \& Stejskal, J. (2018). Propellants of university-industry-government synergy: Comparative study of Czech and Slovak manufacturing industries. Ekonomicky Casopis, 66(10), 987-1001. https://www.proquest.com/schol arly-journals/propellants-university-industry-government/docv iew/2395866396/se-2?accountid=30109

34. Rojo, T., González-Limón, M., \& Rodríguez-Ramos, A. (2019). Company-university collaboration in applying gamification to learning about insurance. Informatics, 6(3), 42. doi: https://doi.org/http://dx.doi.org/10.3390/informatics6030042 35. Runiewicz-Wardyn, M. (2017). Dynamic externalities, universities and social capital formation in the EU biotechnology industry. Management Dynamics in the Knowledge Economy, 5(1), 13-31. Retrieved from https://www.proquest.com/s cholarly-journals/dynamic-externalities-universities-socialcapital/docview/1911175620/se-2?accountid=30109

36. Rybnicek, R. \& Königsgruber, R. (2018). What makes industry-university collaboration succeed? A systematic review of the literature. Journal of Business Economics, 2019(89), 221250. doi: https://doi.org/10.1007/s11573-018-0916-6 37. Secundo, G., Vecchio, P. Del, Schiuma, G., \& Passiante, G. (2017). Activating entrepreneurial learning processes for transforming university students' idea into entrepreneurial practices. International Journal of Entrepreneurial Behaviour \& Research, 23(3), 465-485. doi: https://doi.org/http://dx. doi.org/10.1108/IJEBR-12-2015-0315

38. Yordanova, Z. (2018). User innovation as a basis of innovation network between universities and business TT. International Journal of Innovation, 6(2), 85-96. doi: https://doi.org/http://dx.doi.org/10.5585/iii.v6i2.308

\section{Primary Paper Section: A}

Secondary Paper Section: AM 